\title{
Brentano's Methodology as a Path through the Divide: On Combining Phenomenological Descriptions and Logical Analysis
}

\author{
Tina Röck ${ }^{1}$
}

Received: 22 April 2017/Accepted: 19 July 2017/Published online: 2 August 2017

(C) The Author(s) 2017. This article is an open access publication

\begin{abstract}
In this paper, I will describe how Brentano was able to integrate descriptive philosophy and logical analysis fruitfully by pointing out Brentano's concept of philosophy as a rigorous science. First I will clarify how Brentano attempted to turn philosophy into a rigorous descriptive science by applying scientific methods to philosophical questions. After spelling out the implications of such a descriptive understanding of philosophy, I will contrast this descriptive view of philosophy with a semantic-analytic understanding of philosophy as proposed by Frege. After having thus set the stage I will argue that (1) the current separation of philosophy into the seemingly antithetical strands of (continental) phenomenology and analytic philosophy may be seen as a consequence of how the term 'rigorous science' in 'philosophy as a rigorous science' is interpreted: Does a rigorous science grasp its object with as much exactitude as possible? Or is a science rigorous when its theories are expressed unambiguously, and their implications are drawn with precision? In the course of this investigation I will also point out (2) how Brentano's integrative use of descriptive philosophy (a precursor to phenomenology) and analysis can provide a suitable starting point for an equally successful integration of these methods in contemporary philosophy.
\end{abstract}

Keywords Brentano $\cdot$ Frege $\cdot$ Husserl $\cdot$ Phenomenology $\cdot$ Analytic philosophy · Continental philosophy $\cdot$ Phenomenological descriptions · Descriptive psychology $\cdot$ Logical analysis · Austrian thought $\cdot$ Austrian philosophy

Tina Röck

t.rock@dundee.ac.uk

1 University of Dundee, Dundee, UK 


\section{Philosophy as a Rigorous Science}

In the year 1866, Brentano defended 25 Latin theses for his advanced doctorate (Habilitation). One of these theses was to influence Brentano's entire work (see $\mathrm{ZPh}, 30$ and 75ff), ${ }^{1}$ namely that vera philosophiae methodus nulla sine scientia naturalis est (the true method of philosophy is none other than that of the natural sciences). This insistence that the methods of philosophy should be (at least analogous to) the methods of the natural sciences ( $\mathrm{ZPh}, 45$ and 136) was met with great deal of resistance since it was perceived as form of positivism. ${ }^{2}$ But Brentano did not advocate using the deductive methods of rationalist mechanics ("rationelle Mechanik", ZPh 46) to investigate philosophical problems; instead he had a more Aristotelian, a more descriptive form of science in mind. ${ }^{3}$ The method of natural science, and thus the method that was to be applied to philosophical investigations, merely entailed (1) the gathering of data, (2) the positing of hypotheses on the basis of the gathered data and finally, (3) the analysis of the hypotheses and the deduction of their consequences $(\mathrm{ZPh}, 75 \mathrm{ff}){ }^{4}$ This method is prevalent in more descriptive, classificatory or inductive sciences like Biology, Geology or Oceanography than in rationalist mechanics or in the more contemporary fields of theoretical astrophysics and theoretical quantum physics.

\subsection{Philosophy as a Descriptive Science}

Philosophy as rigorous science, if its conception is based on a more descriptive model, should begin with observation and description. On the basis of the observed and described data, speculative hypotheses are to be formed. In a second step, the adequacy of the hypotheses, their applicability to new situations, their explanatory power, and their consistency with other (already well-proven) theories is investigated, primarily through the means of deduction and analysis. The ideal result of

\footnotetext{
1 In his thesis of 1866 Brentano talks about "natural science" and "philosophy" and in his famous talk on the future of philosophy in the year 1892 he talks about "natural science" and the "science of mind". Questions have arisen about whether Brentano changed his point of view along with his change in terminology. I agree with Gilson when she argues that this change in terminology does not reflect any deeper change of Brentano's position. See Gilson (1955, 59ff).

2 The whole speech published under the title On the Future of Philosophy (ZPh, 1-83) can be understood as an attempt to analyze and disprove a general view of philosophy as incompatible with the method of the natural sciences. In $\mathrm{ZPh}$ Brentano challenges this preconception by attacking a speech to that effect by Adolf Exner, Rektor of the University of Vienna at that time.

3 Brentano's introduction to ZPh emphasizes his impression that many of his contemporaries had the "pure" deductive methods of mechanics or mathematics in mind when talking about the method of the natural sciences (Vorwort to $\mathrm{ZPh}$ and the corresponding footnote 1 by Kraus). In the Addition XII Brentano further challenges the mechanistic preconceptions shaping his contemporaries' views on the methods of the natural sciences and their adequate application to the 'Geisteswissenschaften' ( $\mathrm{ZPh}$, 75-83).

4 According to Brentano much of the resistance to his methodological claim arose because philosophers had a form of rationalist mechanics (also known as analytical mechanics, Weisstein 1898, XV) and thus a very strict version of the hypothetico-deductive model of science in mind, while Brentano actually considered a much more inductive understanding of science to be the adequate methodological model for philosophy as a rigorous science (ZPh, 32ff and 96).
} 
this inductive and broadly Aristotelian method is a theory that adequately accounts for the described data. This approach combines description and analysis in a way that Brentano considers exemplary. Within a more hypothetico-deductive approach to science, as used in rational mechanics or in contemporary theoretical astrophysics, in many approaches to Mathematics and Logic, a theory or a set of hypotheses usually takes precedence over description or observation. This is especially prevalent in scientific reasoning and research, i.e. the work to be done in certain fields of research before any concrete experiments can even be devised or before any descriptive data can be gathered.

Of course, a general and rigorous differentiation between the hypotheticodeductive and the descriptive model of scientific reasoning that Brentano favored appears today to be highly artificial, since in scientific praxis both aspects often go hand in hand. Wherever possible hypotheses are formulated sensitively to data and inductions are made sensitively to possible testable hypotheses. But being sensitive to the data is not equivalent to beginning with a thorough description, and even a quite moderate shift in the role afforded to description can have a huge impact on the results, as I will show in Sect. 3. It does make quite a difference whether one begins an investigation with a phenomenological description of the object of investigation or with a theory, a thought or an assertion about the object, even if these are sensitive to the data. The starting point of any non-descriptive science is at least to a certain extend pre-determined, so it is fundamentally informed by aspects not actually investigated or examined during the investigation at hand. Examples of such pre-determinations can range from previously attained results, to preconceptions, to common-sense intuitions. While for some investigations these can be useful and advantageous, obviously beginning with these is different from beginning with a rigorous description that only notices and accounts for what there is.

So in order to develop a rigorous philosophical method, philosophers need to learn that any investigation has to adapt to the object investigated (sich dem Gegenstande anpasse- $\mathrm{ZPh}, 78$ ) and to the complexity of the specific situation that is to be investigated. This form of adaptation can only be attained through a thorough description because only in description are my categories and concepts formed by the object investigated. But the need for adapting our investigation to the exigencies of the object investigated and its circumstances goes even further. The method of investigation itself has to be determined by the object of investigation and the specific situation investigated. This orientation towards the object and the situation in deciding which method it should be approached with could, for example, be necessary due to a situation being so complex that it cannot be investigated through the means of analysis or deduction alone $(\mathrm{ZPh}, 35)$. Here again, Brentano uses the natural sciences as an example. So if a situation, for example, were too complex to yield exact answers, the natural scientist would adapt his method to the situation and begin with probable answers which he would refine until either a theoretical solution is possible; or, if the answers worked flawlessly in every application, the adequacy of the preliminary answer would be pragmatically proven. If, for example, a die of uniform density had one side that is tilted, the likelihood of the tilted side coming up in Brentano's time could only be gathered inductively and not through computation. Brentano claimed that any natural 
scientist—instead of just giving up his search for an answer-would throw the die until the law of large numbers would justify him in making an adequate claim as to the probability in question, instead of ignoring this problem just because it was not solvable by the means he usually employs ( $\mathrm{ZPh}, 32 \mathrm{ff})$.

Thus, science does not imply [...] that we have to proceed in a uniform way. On the contrary, science instructs and educates us on how to change our methods to conform to the very nature of the objects investigated and to increase our ambitions or to tone them down, to achieve the fuller success in one investigation, renouncing the impossible in another situation, so that the scientifically possible can be reached $(\mathrm{ZPh}, 35) .^{5}$

Within the more descriptive, classificatory or inductive sciences, the focus on the object and its situation most often naturally leads to the adaptation of the methods of investigation to the object of investigation, which is what Brentano demands. In philosophy, only a thorough description could yield similar results: in a comprehensive description, we do not only get to know the objects or facts to be investigated, but we also achieve a sense of what methods might be appropriate for examining these facts. In describing the facts of our experience before analysing and explaining them, we can gain helpful insights into how to adapt our methods and standards to the objects of investigation and the situation they are in. This, of course, implies that in philosophy a rigorous description of the object and its situation should precede the choice of the investigative method to be applied.

\subsection{Is Description an Adequate Method for the Kinds of Objects Investigated in Philosophy?}

A central issue Brentano has to take into account, if his approach is to be taken seriously, is how the objects investigated in philosophy relate to the objects investigated in the more descriptive, classificatory or inductive sciences. Isn't it the case that the kinds of questions philosophers ask about the nature of reality-its essence-concern things that cannot be experienced and thus cannot be described? If that is the case then the methods used in the descriptive sciences are just not helpful in answering philosophical questions. Brentano knew this objection well:

One furthermore claims, that the form of explanation and comprehension the philosopher demands is of a fundamentally different kind than the one natural scientists strive for. These people claim that a philosopher attempts to reach the inner What and How of things, matters not accessible through observation and experience $(\mathrm{ZPh}, 95){ }^{6}$

\footnotetext{
5 My translation of: "Die Naturwissenschaft verlangt also keineswegs, [...], daß wir überall gleichmäßig [...] vorgehen sollen. Im Gegenteil, sie unterweist uns und übt uns darauf ein, der besonderen Natur der Gegenstände entsprechend unserer Verfahren zu ändern und unsere Ansprüche bald zu steigern, bald herabzustimmen, um dort den volleren Erfolg zu erzielen, hier auf das Unmögliche verzichtend, das wissenschaftlich Mögliche zu erreichen".

6 My translation of: "Man sagt weiter, die Weise der Erklärung und Ergründung, nach welcher der Philosoph verlange, sei von ganz anderer Art als die, welche der Naturforscher anstrebe. Der Philosoph
} 
This argument, of course, presupposes a certain understanding of what philosophy is. Departing from such an understanding of philosophy, it is clear that the scientific method of description cannot be considered adequate to resolve philosophical issues. But for Brentano, only philosophers who did not yet know the proper limits of their own field would consider these kinds of objects to be the true philosophical objects and consider the resulting questions to be the only genuine philosophical questions - the reason being that we can never hope to truly know anything about the transcendent world, so it is not a proper object of inquiry, be it scientific or philosophical. But according to Brentano these "transcendent" questions are neither essentially philosophical, nor are they the only kinds of questions philosophers ask (see $\mathrm{ZPh}, 95$ ).

Even though these metaphysical questions were bad examples for illustrating the difference between natural sciences and philosophy, Brentano still concedes one point, namely, that the objects investigated in philosophy are not identical to the objects investigated in the natural sciences. Otherwise, there would be no reason to bother with philosophy. "If one looks closer at the nature of the problems philosophers are concerned with, they appear to possess an entirely different character from those of the other sciences" $(\mathrm{ZPh}, 89){ }^{7}$ So if we look at the nature of the problems that philosophers are concerned with (even those which are within the limits of possible knowledge), philosophical problems will still appear to be very different from the problems investigated in the natural sciences. While the natural sciences are concerned with natural laws and physical, chemical, and biological objects, philosophy is concerned with the laws of logic and language, of psychology, the structures of reality and of values. While it might be enough for a physicist to investigate the data provided by the senses, philosophy also investigates - and this will probably be the philosopher's main focus - the objects of inner perception and, therefore, things like judgements and thoughts $(\mathrm{ZPh}, 79)$. But ultimately the question whether philosophy and the natural sciences are investigating the same kinds of issues or objects is less relevant than the question whether philosophy can profit from the scientific method, even if they do investigate different objects (ZPh, 36).

Brentano argues that the methods used in philosophy can and should be analogous to the methods of the natural sciences, if we want to transform philosophy into a rigorous and exact science $(\mathrm{ZPh}, 43)$. For Brentano this application of the scientific method was eminently possible within the field of empirical psychology, which, according to him, was also the main field for philosophical investigation. It was the discipline within which philosophy as a rigorous science could be most readily achieved because empirical psychology employed the methods used in the natural sciences while its content was genuinely philosophical and within the limits of knowledge (i.e. not transcendent).

\footnotetext{
Footnote 6 continued

wolle in das innere Was und Wie der Dinge eindringen, zu welchem Beobachtung und Erfahrung einen Zugang nicht besitzen".

7 My translation of: "Faßt man die Natur der Probleme genauer ins Auge, mit welchen der Philosoph sich zu beschäftigen pflegt, so scheinen sie von ganz anderem Charakter als die der übrigen Wissenschaften".
} 
Nonetheless for Brentano descriptive psychology and philosophy as a rigorous science are quite distinct, but I think it is quite in line with his investigations to claim that descriptive psychology can be seen as a concrete example of a philosophy employing the kind of scientific method introduced above and thus as a possible example for a kind of philosophy that actually is a rigorous science.

\subsection{Descriptive Psychology as a Method to Attain Self-Evident Truths}

Brentano developed his descriptive psychology, which is a philosophical investigation into the nature of consciousness, using the descriptive methods of empirical science but applying them to the inner perception of phenomena and their givenness in consciousness instead of objective or material entities. And even though the content of descriptive psychology was in no way transcendent or transcendental but based on empirical data, i.e. the concrete perception of phenomena present in consciousness and thus always potentially open to investigation, descriptive psychology, according to Brentano, could lead to evident and indubitable truths, which rendered it a philosophical investigation and not merely an empirical one.

However, the claim that descriptive psychology is a rigorous science that leads to self-evident truths is quite problematic. The first glaringly obvious problem concerns its status as rigorous science and the fact that inner phenomena are not given with the same kind of objectivity as outer phenomena. How to be certain that the truths we gain through descriptive psychology are objective and not merely the result of some flight of fancy, if we cannot observe the inner psychic phenomena with the same amount of objectivity with which the natural scientist can observe the outer natural phenomena (DP, 22)? Brentano has a quite ingenious answer to this objection. The main reason why we strive for objectivity is because we consider objective knowledge about the objective world to be more reliable than subjective knowledge about mental phenomena. But actually, the experience of outer phenomena, i.e. the physical world and the like, is much more uncertain and thus actually less reliable than our perception of inner phenomena. We constantly get things wrong when we base our knowledge on experience of the world alone, and we often are subject to sensory deceptions. So it is quite plain that the perception of physical "objective" phenomena does not lead to indubitable truths. The inner perceptions of one's mental life, however, while not "objective" in the traditional sense, are indubitably true:

We have no experience of that which truly exists, in and of itself, and that which we do experience is not true. The truth of physical phenomena is, as they say, only a relative truth. The phenomena of inner perception are a different matter. They are true in themselves. As they appear to be, so they are in reality, a fact which is attested to by the evidence with which they are perceived. Who could deny, then, that this constitutes a great advantage of psychology over the natural sciences (PES, 19).

However, descriptive psychology also faces the problem that inner observation of current mental acts is impossible, one can only observe inner phenomena after the fact (Moran 2000, 41). Nonetheless, inner perception allows for immediate access 
to the mental phenomena since it "...is the incidental awareness of all my mental phenomena concurrently with being aware of their objects" (DP, xv). So while I cannot observe inner phenomena directly, I can perceive the way objects are given to me in consciousness. So "[i]t is only while our attention is turned toward a different object that we are able to perceive, incidentally, the mental processes which are directed toward that object. Thus the observation of physical phenomena in external perception, while offering us a basis for knowledge of nature, can at the same time become a means of attaining knowledge of the mind" (DP, 22).

Inner perception plays a central role in Brentano's philosophy since it is the infallible empirical basis of descriptive psychology ${ }^{8}$ (Moran 2000, 41). The description of inner perceptions can thus provide access to the laws and essential structures of consciousness. Some results of this kind of investigation are, for example, the insight into the intentional structure of consciousness, or the a priori law that "[n]othing can be an object of judgement unless it is represented to the mind as an idea." (Kraus 1973, 288). Descriptive psychology as a philosophical research program thus implies a search for evident and indubitable truths on an empirical basis. Oskar Kraus attempts to resolve this apparent contradiction implied by the claim that indubitable truths can result from an investigation of empirical data by maintaining that Brentano's method is empirical only insofar as it is based on inner perception. ${ }^{9}$

Thus the results of descriptive psychology were never intended to be merely psychological or subjective. On the contrary, descriptive psychology and its later development in the form of phenomenology were the only sciences that allowed empirical access to evident and indubitable truths and not to merely subjective opinions. The empirical aspect of this method was to eliminate the threats of dogmatic metaphysics and transcendentalism. Additionally, the fact that the discovered laws were self-evident and indubitable in nature was ideal for grounding the objective validity of philosophy as a rigorous science. Even though he was one of the most fervent attackers of Brentano's method, the early Husserl would, on this matter, take up a similar stance.

Thus neither descriptive psychology nor the phenomenological method as conceived by later generations was supposed to lead us to an understanding of merely subjective phenomena or subjective mental acts. In an Aristotelian fashion, descriptive philosophy attempts to describe the invariant structures that are exemplified by singular concrete experiences. The phenomenological method in general attempts to capture the invariant structures of forms of experience, like imagination, perception, dreaming or judging and of their objects by investigating the structures of many concrete singular instances of a certain type of intentional act and the corresponding structure of the contents given in these intentional acts. Phenomenology can, therefore, be called the empirical science of essential

\footnotetext{
${ }^{8}$ Inner perception as the empirical basis for descriptive psychology is supplemented by memories of perceptions: "Indeed, turning one's attention to physical phenomena in our imagination is, if not the only source of our knowledge of laws governing the mind, at least the immediate and principal source" (DP, 22).

${ }^{9}$ Kraus even goes as far as to call the results of descriptive psychology apodictic since it encompasses "evident apodictic cognitions" (Kraus 1973, 288).
} 
structures: "Phenomenological reflection does not produce factual statements or generalizations derived from particular experiences. Instead, it produces descriptions of what is essential or invariant to such-and-such a kind of experience." (Polkinghorne 1983, 42).

\section{The Role of Language and Thought in Rigorous Philosophy}

Brentano's reflections on language were mainly of a methodological nature, as he tried to refine his method to render philosophy a rigorous and exact science. Therefore, he focused on the refinement and clarification of language, of concepts, and arguments, and on the improvement of the logical structures on which the arguments are based. It is this aspect of Brentano's work that influenced analytical philosophers profoundly. ${ }^{10}$ Evidence for this claim can be found in the manifesto of the Vienna Circle The Scientific Conception of the World: The Vienna Circle (Carnap et al. 1973). ${ }^{11}$ In the course of clarifying the historical background of the circle, Brentano is named as the philosopher who opened up the possibility of a renewal of logic, which was needed to "answer logical and the gnoseological problems" of the foundations of physics (Carnap et al. 1973, 302). From the same passages, it is just as evident that the members of the Vienna Circle were much more interested in the logical possibilities Brentano's thoughts had opened up than in the descriptive aspects of his philosophy. But Brentano did not consider all relevant philosophical issues to be logical or semantic in nature, as Frege claimed. In order to understand the rift between Brentano's philosophy as it was transmitted by Husserl and as it was adopted by the emerging group of analytically oriented philosophers, we also need to look at Frege's answers to the questions raised by Brentano.

\subsection{Frege's Arguments Against Descriptive Psychology}

Those thinkers influenced by Brentano who were to develop their thoughts in an analytical fashion tended to move their investigative focus from the description of the phenomenal object as given in the intentional mental act to the propositional content of mental acts and their expression in language. This step is primarily justified by Frege's claim that the philosophically relevant aspect of psychic acts are not psychological at all, but semantic. (Frege 1918-1919, 60) The phenomenon and its appearance for the subject are not what is relevant; rather, it is the meanings that are instantiated by the mental acts in question. This move from the description of the directly accessible phenomenological content to the objective semantic content of

\footnotetext{
${ }^{10}$ In his book Austrian Philosophy, The Legacy of Franz Brentano Smith has elaborated the central role of Brentano's thought for the development of analytic philosophy, which according to him could also adequately be called the "Anglo-Austrian" philosophy. "The central axis of Austrian philosophy, however, which as I hope to show in what follows is constituted by the work of Brentano and his school, [...]" (Smith 1994, 2).

11 The genealogy of Brentano's more direct influence on the development of analytic philosophy runs roughly as follows: from Brentano to Twardowski, Meinong and the Vienna Circle and indirectly to Wittgenstein and Russell. See Smith (1994).
} 
mental acts is one of the fundamental shifts during the beginning of the twentieth century that enabled the development of modern analytic philosophy.

In accordance with these presuppositions the only objective, i.e. not merely subjective, access to thoughts and their propositional contents available to us is the expression of these semantic contents in language. Language, according to Frege, mirrors or expresses our thoughts. And even if language is just a distorting mirror of our mind, it is the only mirror we have (Dummett 1994, 6). As Frege puts it:

I am not here in the happy position of a mineralogist who shows his audience a rock-crystal: I cannot put a thought in the hands of my readers with the request that they should examine it from all sides. Something in itself not perceptible by sense, the thought, is presented to the reader-and I must be content with that-wrapped up in a perceptible linguistic form. The pictorial aspect of language presents difficulties. The sensible always breaks in and makes expressions pictorial and so improper. So one fights against language, [...] (Frege 1984, 360).

Thus the only way to understand our thoughts and their objective content is to investigate the meanings of the words as they are used in sentences, because words only have a meaning in the context of sentences (Frege 1960, xxii). Thus the investigation of sentences becomes essential in understanding the nature of thought and what thought is about, i.e. its semantic content. This apparently simple move substitutes the intentional object of thought possessing a phenomenological character that can be described for the linguistic expression of propositions or for the semantic content of mental acts that can only be analysed as the basis of philosophical investigation.

Many philosophers who were in agreement with Frege's assessment that the central role in philosophical investigations should be afforded to propositions or the semantic content of thoughts also readily followed his conclusion that to answer philosophical questions we need not conduct any tedious descriptions of subjectively experienced phenomenological content, instead we could focus on investigating the objective expression of semantic content in language. Frege himself was very clear on this practical implication of his position. He even went so far as to state that the phenomenal content of a mental act can never be relevant for judgements about the object of the mental act (Frege 1918-1919, 61). Interestingly enough, both Husserl and Brentano could agree with this claim, if we added a distinction. While it is true that phenomenological content cannot directly help us judge what the object of the mental act is irrespective of that mental act, it can help us describe how it is given and distinguish it from other forms of givenness. And these different forms of givenness do allow for differentiations and conclusions also about the object of the mental act. ${ }^{12}$

All that is necessary for beginning a thorough philosophical investigation is the semantic content of the mental act as expressed in language, accessible through the method of linguistic analysis. Thus thinkers influenced by these claims considered

\footnotetext{
12 Husserl explores these relations into great depth via his concept of universal a priori of correlation (e.g. Husserl 1970, §46).
} 
the descriptive moment, that was so central to Brentano's philosophy, to be irrelevant for philosophical inquiry, because phenomenological content and its description were both deemed to be merely subjective. Only an analysis of the objective linguistic expressions of semantic thought content was considered to be able to yield adequate results. Frege's philosophy thus strongly influenced what philosophy was supposed to investigate, by, on the one hand, fostering a general distrust in "merely subjective" descriptions and by considering, on the other hand, only the objective linguistic expression of semantic content an adequate object of philosophical investigation.

\section{Brentano's Integration of Description and Analysis}

Since Brentano endorsed an inductive understanding of science, he was convinced that to render philosophy rigorous, scientific, and clear, observation and an adequate description of what had been observed had to take precedence over any kind of explanation. This focus on description was only the first step toward a philosophy as a rigorous science. As already mentioned, for Brentano the method of natural science implied an ordered series of steps: the gathering and description of data, the positing of hypotheses on the basis of the gathered data, the analysis of the hypotheses, and the deduction of their consequences ( $\mathrm{ZPh}, 75 \mathrm{ff})$. Since descriptive psychology exemplifies the first and possibly also the second step, it can be considered a path towards a philosophy as a rigorous science.

Brentano supposed that a thorough description of the phenomenon or of the domain of phenomena that were to be investigated was necessary before explanation and theory could yield positive results. But not any empirical or observational account is automatically a description, as Brentano understood it. For Brentano the term deskriptiv denotes a very precise way of grasping an object, namely a morphological or classificatory rendering of the object in contrast to genetic, reductive, or explanatory methods. Thus a description in Brentano's understanding does not explain its object by referring to something "beyond" the object it is trying to grasp: it does not refer to the object's cause, its material basis, its genesis, becoming or any other aspect connected to the object that an explanation might refer to. A proper description is only focused on grasping the object as it appears in its form or shape as well as in its relation to other appearing objects.

In Brentano's philosophy the importance of describing phenomena cannot be overemphasised since “...'[d]escriptive' is one of the key words in Brentano's philosophy, [...]. Generally speaking, all the ramifications of Brentano's thought relate in some way or other to this [...]." (Libardi 1996, 44). This is the case because Brentano was convinced that description—as he understood it-could lead to indubitable truths, even if these truths are not immediately given or easily attained.

In what follows I will give some examples of Brentano's combination of both the methods of description and conceptual and linguistic analysis in order to render descriptive psychology as a path toward a philosophy as a rigorous science. 
Brentano identifies six steps that should be involved in any philosophical investigation. These steps are:

(a) He has to experience [erleben],

(b) he has to notice [bemerken],

(c) he has to fix [fixieren] what he notices in order to collect it,

(d) he has to generalize inductively;

(e) where the necessity or impossibility of a unification of certain elements becomes clear from the concepts themselves, he must intuitively grasp these general laws;

(f) finally, we can add that he has to make deductive use of what he gained, in one way or another, from general laws. By doing this, he will be able to solve many questions concerning the elements which otherwise he would scarcely have been able to answer (DP, 31f).

The first step can only be achieved through description, the latter steps only through deduction, generalisation and linguistic as well as conceptual analysis. The steps in between can only be realised if these different methods are combined. In the following paragraphs I will only look at the steps that combine both methods of description and analysis, most obviously (b) noticing and (c) fixing.

For example, habits often prevent or hinder the second step of philosophy as a rigorous science, namely the moment of (b) noticing. "Deceptions by linguistic expressions are prejudices based on habit that in particular need to be identified. It is curious how often they have prevented important scientists from noticing relatively simple things." (DP, 44). Thus "[e]xisting prejudices have to be destroyed. Otherwise it will not be possible to let someone notice something, even though the conditions have been made as favorable as possible in all other respects." (DP, 43). This destruction of habits can happen with reference to experience, as in phenomenology, or through a structural (logical) or semantic analysis of language.

In the case of linguistic habits, for example, both an analytic investigation into the structure of judgments and a phenomenological description can be used to dispel prejudices. One of Brentano's examples for exposing linguistic habits by experiencing and noticing is the following: "Indeed, language often creates a prejudice detrimental to noticing because it lacks a name for a certain fact, like, for example, for the analogue of evidence in certain emotional activities [Gemütstätigkeiten]." (DP, 44f). We experience something, but since there is no linguistic expression for what has been experienced, we tend not to notice it.

The dissolution of linguistic preconceptions through a combination of semantic analysis and experience is hinted at in the following example:

A very complex prejudice [is given in the assumption that a simple name stands for a simple concept]. One is of the opinion that the presentation itself must be simple and fails to notice anything of its complexity. This is so for red, green, etc., or for God where many believe that it is a simple concept because he has been associated with the idea [Vorstellung] of a simple being. Based on linguistic expression there is a prejudice about the nature of judgments (DP, 133). 
Just because we can refer to things with simple names within our judgements we tend to suppose that the concepts need to be simple too. One last example to show where the method of analysis is indispensable for Brentano: "If language uses the same expression, one suspects, by force of habit, that the same process is expressed" (DP , 44). This prejudice can only be dispelled adequately by rigorously analysing the different uses of the same expression in different contexts.

Also in the third step (c) fixing of what has been experienced and noticed both analysis and description should be involved. To fix the results of phenomenological investigations in a logically adequate and semantically meaningful way, we need to keep the exact descriptions in mind to translate them as best we can into expressions and judgements. An analysis of the results, i.e. the judgements and the expressions used to fix the descriptive findings, can help to state the results more clearly by mediating the imperfections of language, like equivocation or vagueness (PD, 72). And an analysis can help to verify whether what has been fixed in language does truly reflect as well as possible what has been noticed. These aspects of the step of fixing are crucial, since the precision and value of the consequent inductive generalisations and the deductive applications of the fixed results depend entirely on this step. Here description and analysis must both be applied in order to form adequate philosophical statements that can be a strong foundation for further generalisations and deductions.

As we have seen, there is more to Brentano's method than mere description. Even though description was central to his program, it alone does not result in a philosophy as a rigorous science, since it should ultimately allow us to gain insight into general laws from which we should be able to deduce relevant information. This means that we have to leave the stable fundament of description in order to make inductive and deductive leaps (DP, 31f). Consequently, descriptive psychology cannot be identified with philosophy as a rigorous science. But the method of description as it is put forward in descriptive psychology is precisely the method that allows us to gather the basic data from which philosophy should begin, if it is to become a rigorous science. With "descriptive psychology" Brentano also delineates the realm appropriate for genuine philosophical enquiry, i.e. he points out the kinds of objects philosophers can adequately describe. Descriptive psychology thus provides the philosophically generated basic statements that retain a strong tie to the phenomena and which provide an adequate basis for philosophical investigations.

\section{Conclusion}

I hope to have shown that what ultimately separates phenomenology from analytical philosophy is not the intellectual rigour or the scientific method, but the focus of investigation. For various reasons phenomenologists contend that we can investigate the things themselves (be it thoughts or physical entities in their givenness) by looking at the way these things are intentionally present as phenomena. They also contend that we can describe these objects with a great degree of exactitude - this exactness in grasping the objects renders philosophy a rigorous science. This main focus of most phenomenological investigations is thus best captured in Husserl's 
famous dictum: "Zu den Sachen selbst!" The description of these things (not to be confused, of course, with Kant's 'Ding an sich'- the thing in itself) as they show themselves is generally considered the ultimate road to come as close to the real, the factual, and the true as possible. For a phenomenological investigation it is generally of less importance whether the singular descriptive sentences are true or not, or if they could even be assigned a truth-value. The relevant criterion for determining the quality, i.e. the accuracy of a phenomenological-descriptive sentence as part of a phenomenological description, is how adequately the whole description fixes the object of the phenomenological investigation. Its final aim is not necessarily to transport a "truth", as any classical judgment would; it might also be to help others notice what they overlooked in their own experience of the object by describing what is generally overlooked and thus pointing it out: "The simplest way [...] to let someone notice something is to identify it by description [namhaft machen]." (DP, 61). Even though logical or semantic analysis of judgments plays an important role in phenomenology — at least it did for Brentano and Husserl—it can never be the ultima ratio of any philosophy based on description, because the relevant sorts of description are not true or false. Such descriptions can only be adequate or inadequate. "Truth" and "falsehood" are absolutes, while adequacy comes in degrees; this is the relevant difference here. Propositions cannot be compared and judged to be 'more true' or 'falser' than other propositions, they are either the one or the other. Two differing descriptions, on the other hand, can both be adequate but vary in their degree of accuracy. Also, there is no such thing as a full description or an absolute description. Any description can be enlarged, improved upon, rendered more accurate and more adequate, while this is not the case with judgments or propositions. Judgments or propositions, when stated clearly and unambiguously, either are or are not true.

Still the importance of semantics and logic for Brentano's project is evident in his insistence on the need for a reformed logic capable of explicating the 'deeper' structures of philosophical language. This is necessary in order for philosophical language to express discoveries made through description with less ambiguity and so that the implications of the judgements based on these discoveries can be deduced rigorously. This aspect of Brentano's philosophy-the emphasis on exact linguistic expression of what has been noticed (Brentano talks about "fixing" and "generalising") and on the precise deduction from what is linguistically expressed-is emphasized in analytic philosophy. But our talking, judging, or thinking about reality was never the ultimate medium of investigation or the ultimate point of reference for Brentano or for the phenomenologists. Linguistic analysis mostly just serves to approach the true goal of phenomenological investigations: an adequate description of the investigated phenomenon in order to enable other people to notice the phenomenon themselves.

A philosopher adopting Frege's point of view in considering this descriptive aspect to be merely subjective, has to remain skeptical on the issue of whether a reformed logic could suffice to overcome the perceived subjectivity in descriptive philosophy and on the issue of whether any phenomenological approach could overcome this methodological flaw. Presupposing a Fregean view of language also encourages doubts about the power of description to dispel the enchantments of 
language and the power of the description of mental acts to provide a pathway to an adequate description of the phenomena and the respective things themselves. Proponents of the linguistic-analytical method usually do not understand their investigations as an attempt to reach the things themselves via the phenomenon. They mainly see their task as the clarification of thoughts or propositions about things by analyzing their expression in language and judgments. And even if I claim here that analytic philosophy is mostly concerned with language and judgments, I am not denying that analytic philosophers have worked extensively on the questions of how these relate to the concrete world or the actual states of affairs especially in later forms of analytic philosophy. All I am claiming is that the judgments, thoughts, or propositions about the world are generally the basis of these kinds of investigations. And their aim is to clarify these judgments, thoughts, or propositions. Usually an analytical philosopher will strive for an adequate definition or explanation of something, and he or she will not aim to describe the things themselves as they are experienced or as they are intentionally given.

Returning to the initial question, we can ask again whether a science is exact if it grasps its object with as much exactitude as possible or if its theories are expressed unambiguously and their implications drawn rigorously? In the case of philosophy this amounts to the following question: is the ultimate aim of philosophy to formulate the perfect argument, to be able to show readers the truth of one's thoughts? Or is the purpose of philosophy to generate a description as accurate as possible, enabling readers to see what there actually is and freeing them from their preconceptions? Looking at Brentano's integrative method, he might well have replied that philosophy as a science is precise only if it (1) grasps its object with as much exactitude as possible and then (2) models its theories and arguments on the grasped object with a focus on unambiguous expression and intellectual rigour.

If someone were to ask me now what made a science rigorous, either precise arguments or accurate descriptions, with Brentano I would answer: the combination of both, obviously.

Open Access This article is distributed under the terms of the Creative Commons Attribution 4.0 International License (http://creativecommons.org/licenses/by/4.0/), which permits unrestricted use, distribution, and reproduction in any medium, provided you give appropriate credit to the original author(s) and the source, provide a link to the Creative Commons license, and indicate if changes were made.

\section{References}

Brentano F (1925) In: Kastil A (ed) Versuch über die Erkenntnis. Meiner, Leipzig

Brentano F (1966) The true and the evident (trans: Chisholm R). Routledge \& Kegan Paul, London

Brentano F (1968) In: Kraus O (ed) ZPh. Über die Zukunft der Philosophie. Meiner, Leipzig

Brentano F (1973) PES. Psychology from an empirical standpoint (trans: Rancurello AC, Terrell DB, McAlister L), 3rd edn. Routledge, London

Brentano F (1995) DP. Descriptive psychology (trans: Müller B). Routledge, London

Carnap R, Hahn H, Neurath O (1973) The scientific conception of the world: the Vienna Circle (1929). In:

Neurath M, Cohen R (eds) Empiricism and sociology. Reidel, Dordrecht

Dummett M (1994) Origins of analytical philosophy. Harvard University Press, Cambridge 
Frege G (1918-1919) Der Gedanke. Eine logische Untersuchung. In: Beiträge zur Philosophie des deutschen Idealismus, vol 2. pp 58-77

Frege G (1960) The foundations of arithmetic (trans: Austin JL), 2nd revised edn. Harper, New York

Frege G (1984) Thoughts. In: Geach H, Kaal E-H, Kluge W, McGuinness B, Stoothoff RH (eds) Collected papers on mathematics, logic, and philosophy (trans: Black M, Dudman V). Blackwell, New York

Gilson L (1955) Méthode et métaphysique selon Franz Brentano. Liberairie philosophique J. Vrin, Paris Husserl, E (1970) The crisis of European sciences and transcendental phenomenology: an introduction to phenomenological philosophy (trans: Carr D). Northwestern University Press, Evanston

Kraus O (ed) (1973) Introduction to the 1924 edition of the Psychology from an empirical standpoint. In: Brentano F (ed) Psychology from an empirical standpoint (trans: Rancurello AC, Terrell DB, McAlister L), 3rd edn. Routledge, London

Libardi M (1996) Franz Brentano (1839-1917). In: Albertazzi L, Libardi M, Poli R (eds) The school of Franz Brentano. Kluwer, Dordrecht

Moran D (2000) Introduction to phenomenology. Routledge, London

Polkinghorne D (1983) Methodology for the human sciences: systems of inquiry. SUNY Press, Albany

Smith B (1994) Austrian philosophy: the legacy of Franz Brentano. Open Court Publishing Company, Chicago

Weisstein J (1898) Die rationelle Mechanik. Wilhelm Baumüller, Wien 